Please quote as: Dünnebeil, S.; Sunyaev, A.; Leimeister, J. M. \& Krcmar, H. (2012): Market Engineering for Electronic Health Services. In: 45. Hawaii International Conference on System Sciences (HICSS), Hawaii, USA. 


\title{
Market Engineering for Electronic Health Services
}

\author{
Sebastian Dünnebeil ${ }^{1}$, Ali Sunyaev ${ }^{2}$, Jan Marco Leimeister ${ }^{3}$, Helmut Krcmar ${ }^{1}$ \\ ${ }^{1}$ Department of Informatics \\ ${ }^{1}$ Technische Universität München \\ Germany \\ \{duennebe $\mid \mathrm{krcmar}\} @$ in.tum.de \\ ${ }^{2}$ Faculty of Management and Social Sciences \\ ${ }^{2}$ University of Cologne \\ Germany \\ sunyaev@wiso.uni-koeln.de \\ ${ }^{3}$ Research Center for IT Design (ITeG) \\ ${ }^{3}$ University of Kassel \\ Germany \\ leimeister@uni-kassel.de
}

\begin{abstract}
Various studies have proven the positive impact of ehealth solutions on treatment success and health care spending. Utilization of e-health is therefore urgently recommended by German health authorities. However, the diffusion of such technologies is currently very low, despite the availability of the underlying technology. A market failure is a likely reason for the unsatisfying situation, as there are currently hardly regular business models for electronic health services. This paper conducts a case study on telemonitoring, which has significant positive impact on patients with chronic heart failure, to illustrate a market engineering approach for e-health applications. The introduced case study is located in a southern German region, where health insurances and a physician network want to establish a telemonitoring solution. We investigate the socioeconomic, technical and legal environment in order to derive a transaction object and build a transaction service. Patients will transfer vital parameters to physicians on a daily base. Caregivers observe patients' health status and compile quarterly reports for the e-health provider. The provider distributes the funds of the health insurances according to the compliance among the stakeholders and adjusts the model on an annual base according to the realized savings. The presented solution can be built upon the emerging German infrastructure for telemedicine and be extended to further regions later.
\end{abstract}

\section{Introduction}

In 2008 the German public health system was the biggest national service industry, responsible for total revenue of $€ 263.2$ billion. Healthcare spending amounted for about $10.5 \%$ of the German gross domestic product (GDP) [21]. According to estimates the spending will rise to $€ 453$ billion in 2020, which will represent approximately $15.5 \%$ of the national GDP by then [18]. Healthcare spending can be divided into public and private funds. The public spending represents the mayor proportion, with about $75 \%$ [28]. In Germany citizens and employers pay solidary funds to public and private health insurances. The funds are distributed quarterly by physicians associations to registered caregivers, according to the recorded treatment of the last quarter. All allowable treatments are fixed in a treatment or medication catalogue ex ante, in order to be refundable [23]. Health systems around the world have seen multiple innovations in the field of electronic health (e-health). The benefits of these applications are proven in many cases [29, 10]. Despite the positive evidence, IT services are currently not part of the German treatment catalogue and can therefore not be billed by caregivers in the regular allowance process. Advantages of e-health in terms of efficiency and treatment quality have been investigated in the applications such as: 
- Telemonitoring, which has strong evidence of being beneficial in various aspects of healthcare. Hospitalization, mortality rate, lack of work, and the overall treatment costs can be reduced tremendously by this e-health application $[15,19]$.

- Prevention of adverse events (medical errors), which cause more casualties than breast cancer, traffic accidents, and AIDS combined, and can be limited significantly by the usage of e-health application $[1,10]$.

- Applications managing the accurate discharge of prescriptions, which show advantages, compared to the traditional medication handling. These help to decrease the rate in unadjusted absolute death rate by $27 \%$ for cardio-vascular patients after one year [22]. Considering the fact that wrong medication in the united States cost $\$ 4.4$ Billion in 2006 [17] and $37.4 \%$ of all adverse events are caused by wrong medication [1], the potential is significant.

Hence, the utilization of such supporting information systems (IS) is urgently recommended by German and European authorities and the diffusion of such technologies is subject of major efforts [10]. However, the diffusion speed of the listed applications is, despite the enormous potential for fund saving, currently very low [9]. The unsatisfying adoption rate of e-health, especially for telemonitoring, indicates a market failure. As the underlying technology is available and the benefits have been proven, a working market to organize and accelerate distribution and adoption is a key element for diffusion. Therefore, the intention of this paper is the development of a sustainable market model for telemonitoring, involving both, consumers and providers of e-health applications. The overall goal is to enable the utilization of e-health technology to improve the overall treatment quality.

We conducted a case study, based on a region in southern Germany with 452,000 inhabitants on 2,847 square kilometers. The region is geographically well definable because of its heterogeneous structure, which makes the region suitable for field testing since it represents the structure of Germany very accurately [32]. The caregivers of the region, their physician network, as well as the health insurance are willing to establish telemonitoring. Therefore, the health insurances want to allocate funds to create a market for telemonitoring in order to encourage companies to supply solutions. The market setup is embedded in the roll-out process of the national electronic health card (eHC) system. German health authorities are currently building a nationwide telematics infrastructure (TI) to connect care providers' IS via a common network [11]. On the basis of the proposed TI, telemedicine services will offer communication, cooperation, and documentation features implemented as web services to ensure pervasive availability and integrity of medical data among the German public health system. In the case of the proposed infrastructure, medical patient data is either stored on central servers or portable carriers (i.e., smart phones and tablet devices) or eHC. The secure infrastructure is considered as a major enabler of electronic health services, e.g., for telemonitoring.

\section{Methodology}

The exploratory nature of this research within the context of a physician network was related to the national roll-out of the eHC and guided the authors to adopt a qualitative and interpretive approach to the inquiry. The empirical part of this research follows an exploratory research design with the intention of generating an empirically motivated market model; it is not the intention to test a given research model (for methodological aspects of explorative research designs see e.g. [4] or [3]). Case study research itself is widely used in IS research (for an approach on how to build theories from case study research see e.g., [8]). Four semi standardized oral interviews were conducted: two with board members of the physician network (the business manager and the chairman who additionally works as a general practitioner) and a further two board members of a health insurance, which insures 80,000 people in the region. Additionally, data from two general practitioners' health information systems were analyzed. The literature on previously conducted research was (where available) also included. The study is still on-going, but the main interviews were conducted in a 2-month period in 2010 as part of the introductory project of the eHC.

\subsection{Market Engineering}

The paper aims to create a market for telemonitoring. Therefore, we use a market engineering approach [31] to achieve the desired market result in the given socioeconomic, technical and legal environment. The desired market result is the best possible monitoring of patients with heart failure, in order to reduce the rate of hospitalization, lack of work and the costs caused by the disease. The possible savings, resulting from prevention of hospital treatments should be distributed to the involved stakeholders. Hence, secure transaction objects, (the monitoring documentation) are designed, the transaction service created for the given micro-, infra- and microstructure of the market. Later evaluation can be done in analysis of the market results. Satisfying market results are achieved, when 
telemonitoring solutions report equal results in the field as clinical studies reported for research projects. The output parameters are set accordingly to be able to judge the market result after setup of the e-health applications.

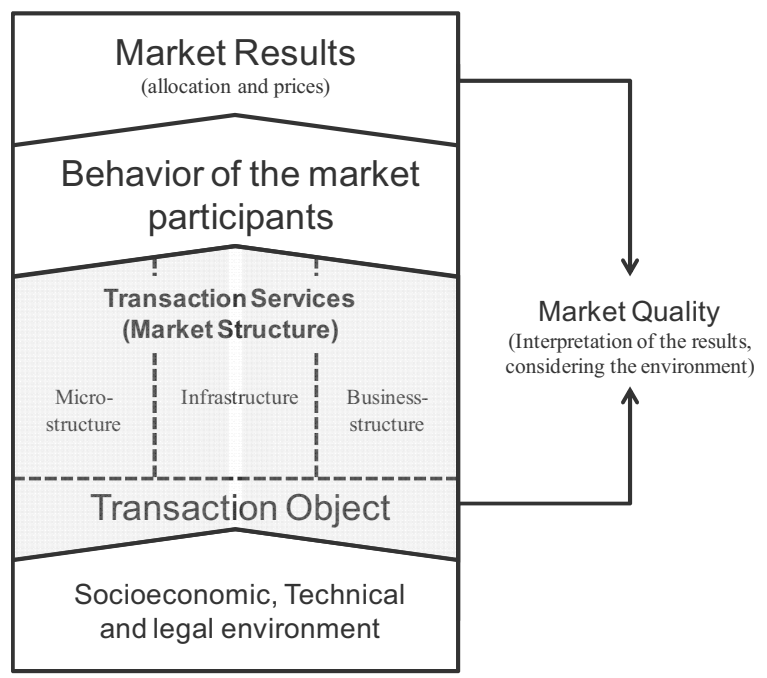

Figure 1 - Market Engineering Framework according to [31]

\section{Case Study}

\subsection{Chronic Heart Failure - Medical background}

Heart failure is one of the most widespread chronic diseases in Germany [27]. The patients' hearts are not able to supply the organism with sufficient blood flow and oxygen to ensure that the human metabolism is working well. In case of chronic heart failure (CHF) the metabolism compensates the low oxygen supply by higher heart rate, vascular stenosis, thickening the myocardial muscle or an increase in blood volume. This can temporarily stabilize the oxygen delivery to the end organs. Patients with compensated CHF temporarily do not show any symptoms of the disease [20]. Decompensation of CHF, caused e.g., by heart attack or pneumonia, leads to fluid retention and uncontrolled hypertension, during rest or light exposure. Medical guidelines provided by the German Medical Association therefore advise daily monitoring of patients' blood pressure, heart frequency and weight [2]. A significant increase in a patient's weight during a short period is e.g. a strong indicator of fluid retention, caused by a decompensation in the case of a heart attack. Also low hypotension (systolic blood pressure) can indicate a decompensation. Early identification of a decompensation allows caregivers to take counteractive measures as early as possible, before the patient's hospitalization because of dyspnea (breathlessness), pulmonary edema or acroedema (water retention in lungs or legs) is inevitable. The application for telemonitoring should support this monitoring action in the best possible manner. Sensors record the vital parameters and transmit them to physicians for monitoring [15].

\subsection{Organizational Setup}

The region in southern Germany counts 452,000 inhabitants. 500 of the 600 ambulatory physicians treating the patients of the region, are organized in a physician network [32]. The physician network has the organizational setup of a $\mathrm{GmbH}$ : a private company limited by shares (the German equivalent to a Limited Company). The network is thereby able to generate revenue, which can then be distributed to the shareholders. All physicians have equal shares in the physician network, and the earnings of such a network are either distributed equally or according to dedicated contracts. The physician network can negotiate treatment contracts with the health insurances of the region directly. This enables physicians to earn money beyond the fixed allowance catalogue of the German ambulatory health system. Two health insurances were contacted by the physician network and asked whether they were willing to set up a market for telemonitoring. Each of the two health insurances has approximately 80,000 insurants. Including the co-insured family members, about half of the inhabitants of the region are insured by either of the two health insurances. Both health insurances, -one a dominant German health insurance and the other the health insurance of a globally operating company with headquarters in the region, are willing to allocate funds in order to enable the market for telemonitoring.

The current legal conditions of the German public health system, which hinder the adoption of e-health, are briefly described in section 4.3.

\section{Environment Studies}

\subsection{Socioeconomic Environment}

In 2006317,000 patients with a diagnosis of CHF lived in Germany. The treatment cost in the same year summed up to $€ 2.9$ billion, which represented about $1.1 \%$ of all national health expenses [21]. CHF furthermore caused the highest number of hospitalizations, reported to be caused a single disease. 
$60 \%$ of all CHF related costs were caused by hospital stays. In $2008 \mathrm{CHF}$ caused 48,918 cases of death, representing a share of $5.8 \%$ of the annual German death rate [27].

Cascading the number of 317,000 Patients with $\mathrm{CHF}$ down to the case study, the region is likely to have about 1700 patients suffering $\mathrm{CHF}$, as the region is representative for Germany. Hence, the physician network is responsible for the treatment of about 1500 patients. 750 of those patients are insured by one of the two health insurances that want to set up a market for telemonitoring. The case study employs estimations, as no detailed data was available during the research. The physician network has 250 general practitioners, which are responsible for monitoring of CHF [2]. Hence, each physician treats approximately three patients with CHF. The numbers from taken from the IS of two caregivers indicated a higher number. Over a period of five years 53 respectively 45 patients with Diagnoses were recorded in the health information system. Despite the variation, the calculation bases on the estimation that three patients with $\mathrm{CHF}$ are monitored in average by one physician.

According to a study on telemonitoring [15], the average annual financial benefit of telemonitoring for one patient with $\mathrm{CHF}$ is at least 3,000 Euros. Considering the total cost of approximately 9,000 Euros per year, a treatment cost reduction of one third can be achieved. Hence, the health insurances try to save money by the avoidance of hospital treatment, which means redirecting funds from hospitalization to prevention by using telemonitoring solutions. If the underlying studies prove to be accurate, which is a basic assumption of this paper, utilization of telemonitoring is more efficient for health insurances than hospitalization. Furthermore, the savings achieved by telemonitoring should be sufficient to cover the additional treatment cost of the physician and the market price of a telemonitoring solution, and thus the health insurances will save money. Initially, a share of one third of the estimated total cost reduction was the saving target of the health insurances when initiating the market. Two thirds should be set up as funds for the provider of the telemonitoring solution. The solution provider will need to partly use the funds as an incentive for patients and caregivers to regularly participate in the monitoring. The payment should depend on the compliance of patients and caregivers. An incentive of one Euro per transaction per patient is suggested here and an incentive of maximal 225 Euros for a caregiver per quarter. This was reported in an interview to be a sufficient amount for a monthly time effort of one hour. As Figure 2 indicates, when monitoring at least three patients with $\mathrm{CHF}$, the additional annual income totals 2,700 Euros. Figure 2 illustrates the financial flow and names the most important stakeholders beside the health insurance: service providers, patients and caregivers.

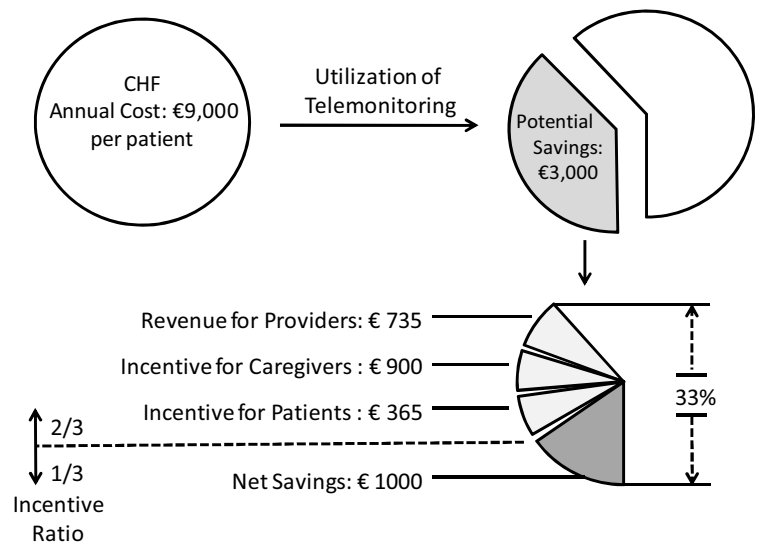

Figure 2 - Financial Environment.

For health insurances, even a zero saving is considered a success, as the treatment quality can be increased when reducing the hospitalization rate. Further the current calculation considers only the actual treatment costs; however, the adjusted expenses for $\mathrm{CHF}$ are much higher. Including the indirect costs, caused by lack of work, the adjusted annual advantage of telemonitoring totals 6,300 Euros per patient [15]. The distribution of the funds to the stakeholders aims to maximize the savings of the annual treatment costs. The total market volume for CHF-telemonitoring in Germany adds up to approximately $€ 230$ million per year. In the region the market volume is only 500,000 Euros, however, the character of a pilot project can justify higher investments.

\subsection{Technical Environment}

In Germany the Telematics Infrastructure (TI) is used as the backbone for the mandatory eHC system. The infrastructure connects existing IS of care providers via a common network [25]. Within the service-oriented architecture (SOA) of the TI, centralized servers or decentralized components provide services, e.g., the encryption, digital signature and authorization of medical data. The primary systems of the TI, i.e., information systems of medical institutions can utilize these services to communicate or collaborate with other care providers to maintain, review or share medical data objects. A local connector component encapsulates all local services as encryption or card access and establishes a secure virtual private network (VPN) connection to the central servers if needed [12]. All individual-related medical 
and administrative data that is uploaded to central servers have to be encrypted, using a hybrid encryption method [13]. The private keys are located on the smart card chip of the eHC and cannot be extracted from there. Hence, they can be used for digital signatures and the encryption of medical data. Decryption of the access key happens within the microchip of the smart card after authorization with a Personal Identity Number (PIN). Patients can use public keys of health care institutions to encrypt the data for the receiver in order to grant them access to their personal medical data. Given, that the receiver of the medical data is a specific physician, the patient needs to access the physician's certificate, either located on the so-called health professional card (HPC), or available via a public key infrastructure. To encrypt the medical data for larger groups of caregivers, e.g., emergency physicians, institutional smart cards, called Smart Media Card hold private keys of institutions [12].

The patient related requirements for the development of the TI are derived from legal conditions in the German code of social law [6]. Following the political goals of achieving high patient involvement in medical processes, patients are required to be in full control of their data. They have to agree on collection, usage and processing of their medical data for each service and care provider ex ante. In order to warrant this requirement, the medical data need to be encrypted with the public key of the source patient and is therefore solely accessible with the private key stored on the patient's smart card [13]. It is thus a mandatory requirement for the TI that patients can view all their data and the record of its usage. To ensure that patients could exercise these legally granted rights, patient interfaces were suggested. An internetbased front end for home usage was announced in the initial architecture [11]. A citizen frontend for the new German ID-Cards was already released that was compatible with the eHC. This software can be employed to transfer data from patients' locations to caregivers. Available also are sensors that can transmit data of weight, blood pressure and heart rate to caregivers.

\subsection{Legal Environment}

Markets organize the flows of materials and services in between individuals and institutions according to demand, supply and external mechanisms. Market forces determine design, price, quality and delivery time of products and services. The buyers demand goods and services according to these parameters and their personal requirements and therewith implicitly regulate markets [24]. Health systems in contrary are characterized by an organized flow of funds from citizens and companies to various caregivers. The flow is regulated by various public mechanisms and institutions [23]. Public Health Systems therewith differ from normal markets as: (1) they normally offer unlimited access to the services offered in the public health system, (2) show information asymmetries between the suppliers (caregivers) and consumer (patients) of health services and (3) the future personal health status of their customers is uncertain, and subject to random fluctuations. These characteristics in sum lead to market failure [30].

In Germany authorities established a public health fund, which is equally financed by employees, employers and receives a tax money subvention. The fund pays a standard amount to health insurances for each insured citizen. Treatment and medication are part of a fixed service portfolio, which has to be reimbursed by all health insurances according to a standardized point value, called "Einheitlicher Bewertungsmaßstab" (EBM). There are further direct contracts between health insurances and caregivers that allow the funding of additional health services and treatments. The health insurance can collect an extra amount of money from their insurants and distribute financial surpluses in order to achieve some competitive advantages and diversification [23].

\section{Transaction Objects}

Medical information is highly confidential data, which must, according to the regulation in the German law, not be processed without the patients' agreement. Furthermore, health insurance must not be in control of all transaction objects, even though they finance the information object [5]. The interviewers therefore recommends splitting the information object in three different objects, each processed in between two of the major stakeholders.

The first transaction object is derived from the medical recommendation settled in medical guidelines in order to achieve the best possible monitoring of patients with CHF [2]. The transaction object directly follows a paper based recommendation developed by the Heart Failure Association of the European Society of Cardiology [16]. It consists of a daily recording of weight, heart rate, and blood pressure (diastolic and systolic). It is compiled at the patients' side during the monitoring and transmitted to the general practitioner for pure medical purposes (Figure 3). Goal is an automated handling of this transaction object to improve acceptance and compliance of the technology in the daily routines of the patients with CHF. 


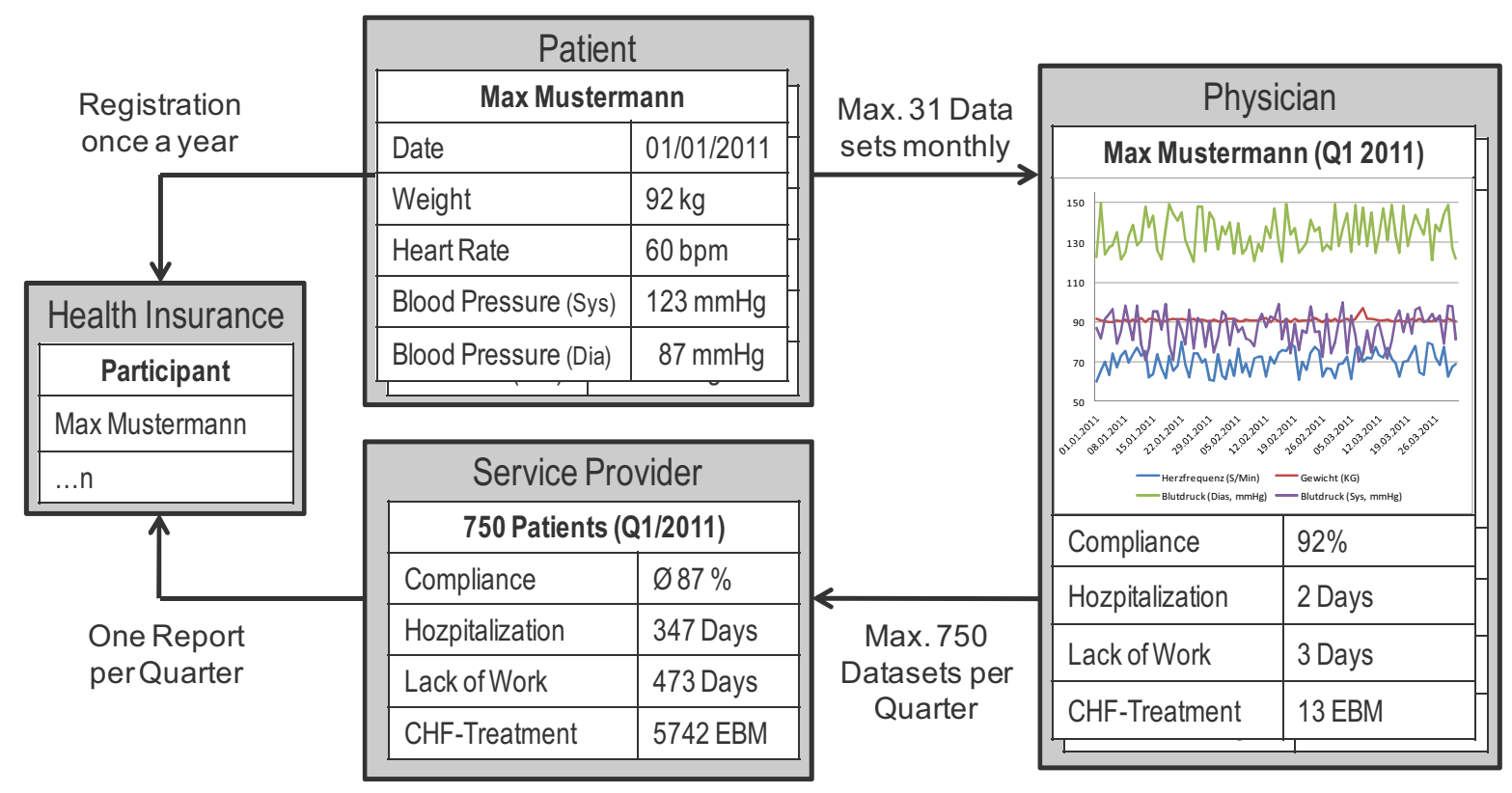

Figure 3 - Telemonitoring transaction object (own illustration)

Precondition is the patient's registration to the program, which is not mandatory. Patients agree on the financial benefits and the processing of anonymous measures to the health insurance and the service provider. Caregivers receive the monitoring record once a day. The caregivers compile the data continuously into a diagram which helps to supervise patients' status of health. At the end of each quarter, caregivers create a report for each patient. Lack of work, monitoring compliance, hospitalization and the CHF related treatments are added to the report, which is the second transaction object and processed to the service provider. The data enables providers to organize the accounting and integrate global measures. The global measures contain overall data of all patients with CHF and enable the health insurance to monitor the success of the market and adjust the incentive structures accordingly.

\section{Transaction Services}

\subsection{Microstructure and Infrastructure}

Due to the introduction of the eHC in Germany and the region's character as a testbed, the implementation of the application should be based on the German TI. The following use case was the suggested microstructure for the telemonitoring solution. Figure 4 shows its integration into the TI:

\begin{tabular}{|c|l|}
\hline Nr. & Activity \\
\hline 1. & $\begin{array}{l}\text { Patients monitor of weight, heart rate, and } \\
\text { blood pressure daily. }\end{array}$ \\
\hline 2. & $\begin{array}{l}\text { Sensors transfer the vital parameters to the } \\
\text { patient's computer. }\end{array}$ \\
\hline 3. & $\begin{array}{l}\text { Patients encrypt the data for their caregiver } \\
\text { and transfer it to the medical server. }\end{array}$ \\
\hline 4. & $\begin{array}{l}\text { The medical service flags the data for the } \\
\text { caregiver and sends a notification. }\end{array}$ \\
\hline 5. & $\begin{array}{l}\text { The physician checks the medical service } \\
\text { and downloads the monitoring record. }\end{array}$ \\
\hline 6. & $\begin{array}{l}\text { The physician decrypts the data each } \\
\text { working day and transfers it to his IS. }\end{array}$ \\
\hline 7. & $\begin{array}{l}\text { The physician validates the data within his } \\
\text { IS and judges the patient's health status. }\end{array}$ \\
\hline 8. & $\begin{array}{l}\text { The physician consults the patient } \\
\text { personally, in case it is required due to } \\
\text { monitoring data. }\end{array}$ \\
\hline 9. & $\begin{array}{l}\text { The physician compiles a report and submits } \\
\text { it to the accounting service each quarter. }\end{array}$ \\
\hline 10. & $\begin{array}{l}\text { The service provider downloads all reports } \\
\text { and inserts measures in the overall } \\
\text { monitoring sheet. }\end{array}$ \\
\hline 11. & $\begin{array}{l}\text { The service provider compiles a report and } \\
\text { transfers it to the health insurance. }\end{array}$ \\
\hline
\end{tabular}

Table 1 - Telemonitoring Use Case 


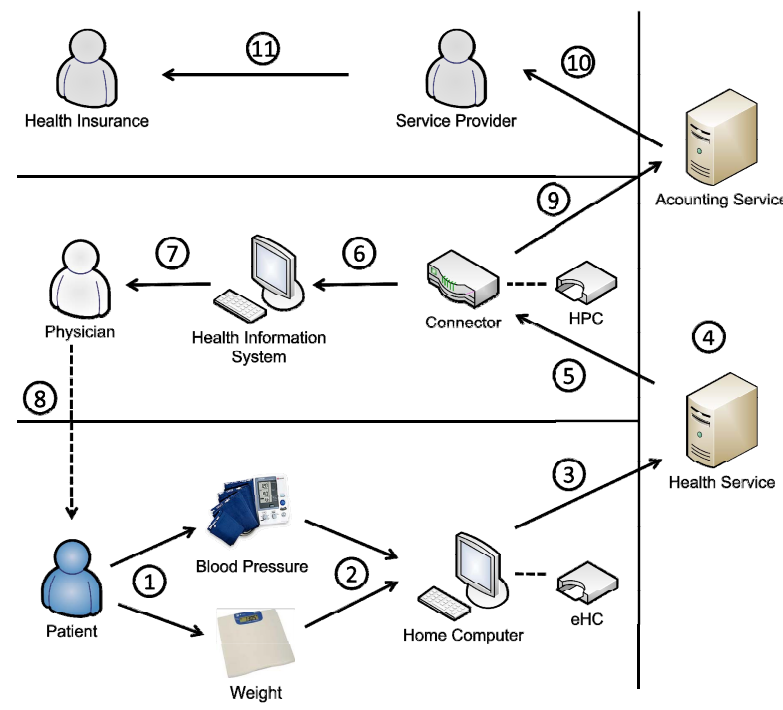

Figure 4-Communication structure

The implementation is based on SOA, with two centralized web services. These are hosted by the physician network due to caregivers' distrust of private institutions and health insurances concerning storage of health related data [7]. The health service allows encrypted communication between patients and physicians, while the accounting service supports the communication between the service provider and the caregivers. Service-oriented device integration of sensors is possible [26], as the data is encrypted by the eHC and decrypted with the physicians HPC according to the description in section 4.2 .

\subsection{Business Structure}

The business structure was already roughly described in section 4.1 and reflects the payments and fees to regulate the market in order to achieve the desired outcomes [31]. In our case, the financial flow is an adverse flow of the transaction objects, developed in the previous chapter. Monitoring information objects are paid within this structure by the health insurance, encouraging physicians and patients to perform and document the CHF prevention thoroughly. As prevention is potentially more efficient than treatment of $\mathrm{CHF}$, the health insurances want to redirect treatment funds of $\mathrm{CHF}$ to the market for telemonitoring. A contract between the service providers and the health insurance is designed and adjusted to support this objective in the best possible manner. In the first year of the telemonitoring contract (period $t_{1}$ ) the health insurance is not able to estimate the savings to be achieved by telemonitoring exactly, however, the cost of CHF for the preceding year (period $\mathrm{t}_{0}$ ) can be quantified by reviewing the past spending for CHF treatment in hospitals and ambulatory care. To allocate funds for the first year $\left(t_{1}\right)$ and initiate the market, the potential savings measured in the studies are taken as the calculation base for the following year. The initial fund for the period $t_{1}$ will allocate one third of all CHF-related costs in $\mathrm{t}_{0}$, as this approximately reflects the estimated saving [15]. Generally, annual readjustments of the market will ensure that the savings achieved in the previous period $\left(t_{n-1}\right)$ are distributed to the stakeholders in the current period $\left(t_{n}\right)$. The annual spending for CHF result from the total treatment costs in ambulatory care, measured in EBM, and the hospital cases related caused by CHF. In Germany health insurances pay allowances for hospital cases based on a diagnosis. CHF has three different hospital cases priced between $€ 2382$ and $€ 4242$ [14] covering all hospital expenses with little exceptions [23]. Furthermore, certain treatments and medication in ambulatory care can be associated with CHF and quantified in an EBM-value directly [15]. Savings in the later periods result from the difference of treatments in the actual period in comparison to the reference period before the establishment of telemonitoring (Formula 1).

$$
\begin{gathered}
\text { Saving } \mathrm{t}_{\mathrm{n}}=\operatorname{CostCHF}_{\mathrm{to}}-\operatorname{CostCHF}_{\mathrm{tn}}= \\
\left(\sum \mathrm{EBM}_{\mathrm{to}}-\sum \mathrm{EBM}_{\mathrm{tn}}\right)+ \\
\left(\sum \text { Hospital Cases }_{\mathrm{t} 0}-\sum \text { Hospital Cases }_{\mathrm{tn}}\right)
\end{gathered}
$$

\section{Formula 1 -Calculation of savings in $t_{n}$}

Lack of work and medication related to CHF can be included into the savings gained by the telemonitoring market. The items are neglected for now, since an inclusion of employers would be necessary and medication data was not available during the study. Additionally, an adjustment factor for the initial costs of CHF in period $\mathrm{t}_{0}$ might be necessary because the cost for CHF increases continuously due to the demographic shift in Germany.

Service providers will pay parts of the total savings calculated in formula 1 to caregivers and patients. The distribution of the savings among the stakeholders was agreed to be $30 \%$ for physicians and $12 \%$ for patients. The allowance for physicians (formula 2) is therefore the sum of all savings achieved for their patients by telemonitoring. Each summand consists of the product of their gain sharing (0.3), their compliance factor and the savings, divided by the payment division, which is agreed. In our case the allowance in $\mathrm{t}_{1}$ will be paid four times (each quarter) and will be $30 \%$ of the saving, which was estimated to be $€ 3,000$. In case of full 
compliance (> $80 \%$ ), the compliance factor is agreed to be 1 . This would lead to a quarterly amount of $€ 225$ per patient and $€ 900$ over the whole year. With the estimated treatment of three patients, a total amount of $€ 2700$ could be earned, if all patients of the region subscribed to telemonitoring and participated with high compliance.

$\sum_{i=1}^{n} \frac{\text { gain sharing } \mathrm{i} \times \text { compliancefactor } \mathrm{i} \times \text { saving }}{\text { payment division } \mathrm{i}}=\sum_{i=1}^{3} \frac{0,3 \times 3000 \times \text { compliance } i}{4}$

Formula 2 - Allowance caregivers in $t_{1}$

The allowance for the first transaction object, the vital parameters transferred from patients to their physicians, is paid on a monthly basis to the patients by deducting it from the monthly insurance premium or the extra premium (formula 3). Patients are paid $12 \%$ of initial savings (gain sharing $=0.3$ ) in $t_{1}$ if they reach a compliance factor of one.

$\underline{\text { gain sharing } \times \text { compliancefactor } \times \text { saving }}=\underline{0,12 \times 3000 \times \text { compliancefactor }}$ payment division 12

Formula 3 -Allowance patients in $t_{1}$

In period $t_{2}$ the whole process will be adjusted according to the market results. These are determined by the behavior of the market participants [31]. Currently the market model expects that the saving potential is high enough to ensure a sustainable telemonitoring of CHF without extra funds from the health insurance. Other cased might require extra funds, but the medical use could justify the allocation also in such cases.

\section{Conclusion}

The German health system has currently no regular market model for e-health. The paper illustrated how health insurances and physician networks can create a market for electronic health services, to harvest the benefits identified in clinical studies. Allocating funds for e-health solutions within a market engineering approach can create a well defined market, including secure transaction objects and predefined transaction services. Medical studies can be employed at first to estimate the initial efforts and long term saving potentials, which can be achieved by e-health applications. In case of CHF existing studies indicate that potential fund savings are sufficient to finance a new market just by the increase in treatment efficiency. The case study has a facilitating environment, as a big physician network could encourage the caregivers of a region to participate in a pilot project. Further, they can sign contracts for multiple caregivers, which is difficult to achieve for single physicians or small physician networks. Since close contact already existed between health insurances and the physician network, there was an organized exchange between the important stakeholders. The approach is not necessarily limited to telemonitoring, as market engineering needs to consider several specific aspects and is therefore difficult to generalize. In any case, market engineering approaches seem to be an approach to create sustainable business models for e-health applications and overcome the low adoption of information technology in healthcare. Successful pilots can move successful e-health applications to the regular allowance portfolio of the health insurance.

\subsection{Limitations}

The current state of the German TI does not yet allow for a setup according to the microstructure suggested in this paper for all caregivers in Germany. Therefore, an extended roll-out of the TI must be ensured in order to enable such a setup on a regular base. It must be further ensured that necessary treatments, medications or hospitalizations are not neglected due to the financial incentive mechanism. Lack of work could not be included in the market, as companies were not yet asked to support the utilization of e-health solutions. Also it is currently legally difficult to pay allowance directly to patients with chronic diseases, a benefit which healthy patients do not receive.

\subsection{Further research}

Within the research project specification, set up and evaluation of the market for telemonitoring is the upcoming target. Furthermore it is necessary to fix the catalogue of CHF-related treatments and medication to specify the model in detail. As the region will be a testbed for the eHC in 2012, the solution can be piloted before a possible roll-out in other parts of Germany. The effect of the market on the adoption of telemonitoring solutions will be an interesting subject of research as well as the adjustment of the market parameters after the first evaluation of the market results.

\subsection{Contribution to Theory}

The case of telemonitoring illustrates how a regular incentive model for the development and diffusion of e-health solutions can be achieved within a public health system. The presented case study illustrates a process on how to translate promising clinical studies 
for e-health applications into transaction objects and allocate funds to stimulate the transmission of this information. The creation of the market for information objects requires initial funds in period $t_{1}$; these can be derived from clinical studies and economical information. The evaluation on the information objects in period $t_{n}$ leads to a readjustment of the technology. Hence, the method adopts a general market engineering approach to the case of e-health in ambulatory care.

\section{Acknowledgment}

The market engineering case study was conducted in the context of the research project "Nutzen und Sicherheit der elektronischen Gesundheitskarte in der Baymatik (NuSiB)" in cooperation with the physician network GO IN located in the region of Ingolstadt. The project is funded by the Bavarian Ministry of Environment and Health.

\section{References}

[1] J. M. Aranaz-Andrés, C. Aibar-Remón and J. VitallerMurillo, "Incidence of adverse events related to health care in Spain: results of the Spanish National Study of Adverse Events", Journal of Epidemiology and Community Health, 62: (2008), pp. 1022-1029.

[2] Ärztliches Zentrum für Qualität in der Medizin, Nationale VersorgungsLeitlinie Chronische Herzinsuffizienz, Bundesärztekammer, Kassenärztliche Bundesvereinigung, Arbeitsgemeinschaft der Wissenschaftlichen Medizinischen Fachgesellschaften, Berlin, 2009.

[3] F. Becker, "Explorative Forschung mittels Bezugsrahmen ein Beitrag zur Methodologie des Entdeckungszusammenhangs", Empirische Personalforschung: Methoden und Beispiele, 111-127 (1993).

[4] J. Bortz and N. Döring, Forschungsmethoden und Evaluation für Human- und Sozialwissenschaftler, Springer, Berlin, 2002.

[5] Bundesministerium für Gesundheit, The German eHealth Strategy (Target and strategy, concept, legal framework, activities/roll-out plan, costs and return of investment, European perspective), Berlin/Bonn, 2005.

[6] Bundesrepublik Deutschland, Sozialgesetzbuch (SGB) Fünftes Buch, Gesetzliche Krankenversicherung, 1988.

[7] S. Dünnebeil, A. Sunyaev, J. M. Leimeister and H. Krcmar, Strategies for development and adoption of EHR in German ambulatory care, 4th International Conference on Pervasive Computing Technologies for Healthcare (PervasiveHealth), IEEE, Munich, 2010, pp. 1-8.
[8] K. M. Eisenhardt, "Building Theories from Case Study Research", Academy of Management Research, 14 (1989), pp. 532-550.

[9] European Comission, Business Models for eHealth, in I. f. H. Unit, ed., European Commission DGINFSO ICT for Health, Luxembourg, 2010, pp. 44-47.

[10] European Comission, EuropäischeUnion (2007) eHealth for Safety Report, in O. f. O. P. o. t. E. Communities, ed., Luxembourg, 2007.

[11] Fraunhofer Institut, Spezifikation der Lösungsarchitektur zur Umsetzung der Awendungen der elektronischen Gesundheitskarte, Fraunhofer, Projektgruppe FuE-Projekt, 2005.

[12] gematik, Einführung der Gesundheitskarte Gesamtarchitektur, gematik GmbH, 2008.

[13] gematik, Übergreifendes Sicherheitskonzept der Telematikinfrastruktur, Specification, 2008.

[14] W. Hellmann and S. Eble, Ambulante und Sektoren übergreifende Behandlungspfade: Konzepte / Umsetzung / Praxisbeispiele, 2009.

[15] T. Helms, J. Pelleter and D. Ronneberger, "Telemedizinische Betreuung chronisch herzinsuffizienter Patienten am Beispiel des telemedizinischen Patientenbetreuungs- und -schulungsprogramms „Telemedizin fürs Herz“", Herz, 32 (2007), pp. 623-629.

[16] HFA, Überwachung der Herzinsuffizienz - Tabelle für die Kontrolle der Krankheitszeichen, Heart Failure Association of the European Society of Cardiology, 2010.

[17] IOM, Identifying and Preventing Medication Errors Institute of Medicine, in INSTITUTE OF MEDICINE OF THE NATIONAL ACADEMIES, ed., THE NATIONAL ACADEMIES PRESS, Washington D.C., 2006.

[18] J. Karette, K. Neumann, F. Kainzinger and K. Henke, Innovation und Wachstum im Gesundheitswesen, in $\mathrm{R}$. Berger, ed., München, 2005.

[19] K. Kempf and C. Schulz, Telemedizin bei Diabetes: Höhere Therapiezufriedenheit, verbesserte Stoffwechselparameter, DiabetivaR Studie Monika Dienstle, WDGZ, 2008.

[20] H. Krum and W. T. Abraham, "Heart failure", The Lancet, 373 (2009), pp. 941-955.

[21] KVB, Grunddaten zur vertragsärztlichen Versorgung in Deutschland, in K. Bundesvereinigung, ed., Berlin, 2008.

[22] J. M. Lappé, J. B. Muhlestein, D. L. Lappé, R. S. Badger, T. L. Bair, R. Brockman, T. K. French, L. C. Hofmann, B. D. Horne, S. Kralick-Goldberg, N. Nicponski, J. A. Orton, R. R. Pearson, D. G. Renlund, H. Rimmasch, C. Roberts and J. L. Anderson, "Improvements in 1-Year Cardiovascular Clinical Outcomes Associated with a Hospital-Based Discharge Medication Program", Annals of Internal Medicine, 141 (2004), pp. 446-453.

[23] M. Lisac, L. Reimers, K.-D. Henke and S. Schlette, "Access and choice - competition under the roof of solidarity 
in German health care: an analysis of health policy reforms since 2004", Health Economics, Policy and Law, 5 (2010), pp. 31-52.

[24] T. W. Malone, J. Yates and R. I. Benjamin, "Electronic markets and electronic hierarchies", Commun. ACM, 30 (1987), pp. 484-497.

[25] M. Marschollek and E. Demirbilek, "Providing longitudinal health care information with the new German Health Card - a pilot system to track patient pathways", Computer Methods and Programs in Biomedicine, 81 (2006), pp. 266-271.

[26] C. Mauro, A. Sunyaev, J. M. Leimeister and H. Krcmar, Service-orientierte Integration medizinischer Geräte- eine State of the Art Analyse, Wirtschaftsinformatik, Vienna, 2009, pp. 119-128.

[27] T. Neumann, J. Biermann, A. Neumann, J. Wasem, G. Ertl, R. Dietz and R. Erbel, "Herzinsuffizienz: Häufigster Grund für Krankenhausaufenthalte", Deutsches Ärzteblatt, 106 (2009), pp. 269-275.

[28] OECD, OECD Health Data 2010: Statistics and Indicators, in Directorate for Employment Labour and Social Affairs, ed., 2010.

[29] P. Shekelle, S. C. Morton and E. B. Keeler, Costs and Benefits of Health Information Technology, Evidence Report - Technology Assessment, 2006, pp. 1-71.

[30] P. C. Smith, A. Stepan, V. Valdmanis and P. Verheyen, "Principal-agent problems in health care systems: an international perspective", Health Policy, 41 (1997), pp. 3760 .

[31] C. Weinhardt, B. Schnizler and S. Luckner, "Market Engineering", WIRTSCHAFTSINFORMATIK, 45 (2003), pp. 635-640.

[32] ZTG, Testregionen in Deutschland, Zentrum für Telematik im Gesundheitswesen GmbH, 2009. 